\title{
The Community Action Framework in Practice: An Illustration Based on the Ready by 21 Coalition of Austin/Travis County
}

\author{
Raphael Travis Jr. (a) \& Tamara G. J. Leech (b)
}

a) School of Social Work, Texas State University, San Marcos, Texas, USA

b) Department of Sociology, Indiana University - Purdue University, Indianapolis, Indiana, USA

\begin{abstract}
The field of positive youth development has expanded focus from articulating and measuring desired manifestations of positive well-being to assembling the environmental conditions known to promote these desired outcomes. Evidence of the effectiveness of community-level efforts promoting positive youth development is still emerging, in particular theory-driven examples of community-driven youth development. This study examined the Community Action Framework, one theory-based community youth development model, through the experiences of the Ready by 21 Austin/Travis County coalition (RB21). The coalition connects youth-serving organizations and also regional coalitions, while promoting the positive development of area youth. Participant observation, interviewing, and archival strategies were integrated to capture information related to the complex and dynamic coalition. Results indicated that RB21 represents a practical and meaningful application of the Community Action Framework. Specific examples and recommendations are provided as guidance for other community level youth development efforts.
\end{abstract}

Keywords: youth development, community action, coalition, capacity building, out-of-school time (OST) programs, program quality

This is the author's manuscript of the article published in final edited form as:

Travis Jr, R., \& Leech, T. G. J. (2011). The Community Action Framework in Practice: An Illustration Based on the Ready by 21 Coalition of Austin/Travis County. Journal of Community Practice, 19(3), 252-273. http://doi.org/10.1080/10705422.2011.595288 


\section{The Community Action Framework in Practice: An Illustration Based on the Ready by 21 Coalition of Austin/Travis County}

Over the past 20 years, individual youth-serving organizations have moved away from the mere prevention of negative health and risk behaviors as they have begun to more actively promote positive well-being over the life course (Imm, Kehres, Wandersman, \& Chinman, 2006; Lerner et al., 2005; Zief, Lauver \& Maynard, 2006). Validation of the efficacy of these positive youth development (PYD) strategies in out-of-school time (OST) programs has led to the development of broader community level coalitions seeking to advance the benefits of PYD strategies. These coalitions complement the PYD paradigm, as coalitions easily allow programs to bridge resources across time and ecological levels. In this way, youth-based coalitions have been central to further entrenching the aforementioned paradigm shift (Kotloff \& Korom-Djakovic, 2010; Walker \& Arbreton, 2001).

Coalitions offer additional benefits to PYD efforts. They can minimize duplication of services, help programs to leverage resources, and increase the advocacy potency for a common cause (Imm et al., 2006). Recent evidence suggests that the greatest benefits occur when coalitions adopt a theory-based model with clear goals and data monitoring capacities. These theory-driven organizations have been shown to affect greater, more positive, change for participating youth than other organizations (Arthur et al., 2010). Some coalitions have explicit theory to guide practice, while others have implicit theoretical foundations.

This study builds on prior work examining both explicitly implicitly theory driven youth development coalitions. We investigate how well one grassroots coalition's implicit theoretical framework and operations correspond to the explanatory dimensions of Gambone and Connell's (2004) Community Action Framework (CAF). Our study elaborates upon the CAF and its principles for improving long-term PYD. We illustrate clear parallels, as well as contrasts, between the framework and the coalition's activities. Our results provide practical strategies for other coalitions to consider.

\section{PYD}

PYD refers to a perspective for conceptualizing strengths-based short- and long-term outcomes for youth. The premise is that strategies that best meet the needs of youth and adolescents work toward positive manifestations of well-being in contrast to simply eliminating risk or potential harm (Damon, 2004; Lerner et al., 2005). In this way, PYD is an example of how a resilience perspective can be more illuminating than a risk perspective. A resilience perspective begins from the assumption that, with proper social support, youth develop a self-righting mechanism to address risk (Benard, 1997; Brackenreed, 2010). This self-righting mechanism helps youth to properly navigate stressful situations and avoid engaging in risky behavior when presented with the opportunity (Blinn-Pike, 1999; Brennan, 2008). Scholars utilizing the PYD perspective have further advanced the resilience perspective by providing concrete examples of self-righting mechanisms (Benson, 2002; Jelicic, Bobek, Phelps, Lerner, \& Lerner, 2007; Oman et al., 2004) and extending considerations of outcomes beyond adolescence.

The current state of research on PYD demonstrates its validity, as well as its correlation with selfregulating (i.e., low-risk) behaviors (Lerner et al., 2005; Scales et al., 2000). We now have a clearer understanding of some of the ways youth manifest these abilities; for example, through competence, character, confidence, connection, and caring (Brooks-Gunn, Duncan, Klebanov, \& Sealand, 1993; Lerner \& Castellino, 2002). A new wave of empirical data further helps to elucidate the ways these characteristics extend into longer term developmental outcomes, or thriving (Lerner et al., 2005). Overall, the PYD literature indicates that instilling aspects of resilience in youth has positive benefits that persist into adulthood (Yancey, Grant, Kurosky, Kravitz-Wirtz, \& Mistry, 2010). 
PYD does not occur in a social vacuum. The development or strengthening of internal assets depends, at least partially, upon external assets at multiple ecological levels (familial, school, neighborhood) (Resnick et al., 1997). With this in mind, various, broad initiatives have sought to integrate developmental processes into programs targeting youth's developmental settings. Early in the history of PYD research, Roth and Brooks-Gunn (1998) identified three critical features of these types of programs: developmental goals, sufficient duration (at least 1 year), and specific activities with opportunities to build skills and broaden horizons. Implicit in these successful strategies is the persistent interplay between person and environment, with youth and multiple ecological levels building positively upon one another (Lerner \& Castellino, 2002).

In this article, we provide a case study of one of these broad initiatives targeting youths' developmental settings: The CAF. The CAF was comprehensively introduced by Gambone, Klem, and Connell (2002) and provides an accessible model that attempts to take all of PYD's elements into consideration. It has been recognized by youth development advocates and scholars as an example of a comprehensive model with the potential to achieve the primary goals of PYD: immediate and long-term well-being of youth (Gambone \& Connell, 2004; Pittman, 2009). However, wide-scale implementation of the model could be hampered by the distance between theory and practice.

The existing literature on CAF is only beginning to offer concrete examples of its implementation (Gambone \& Connell, 2004; Gambone et al., 2002). This study presents the experiences and activities of one coalition, Ready by 21 Austin/Travis County (RB21), to concretely demonstrate the utility and challenges of the CAF as an applied model.

\section{THE CAF}

Gambone and colleagues (2002) developed and continue to research the CAF, a community-based model for improving youth health and well-being (Figure 1). The CAF considers the macro realities of developing systematic strategies to enhance the supports and opportunities known to facilitate short- and long-term PYD (Gambone et al., 2002). Benson (2002) similarly described a process of organizing supports, opportunities, and ecological contexts to strengthen the developmental infrastructure of youth. However, the CAF aims to guide youth development stakeholders' efforts to (a) plan and organize a complex and multifaceted youth serving initiative, (b) improve and sustain program strategies for optimizing PYD and (c) evaluate and act upon successes and shortcomings.

The CAF is novel because of its comprehensive nature. The multilevel orientation takes into account youth, families, and communities' access to, knowledge about, and mobilization of resources. Furthermore, the framework recognizes and addresses all of the life stages of community action efforts. The flow of the chart in Figure 1 can be thought of as representing the progression of community programs from the planning stage (Boxes $E$ and $D$ ) to the implementation stage (Box C) and through the evaluation stage (Boxes B and A).

The planning and implementation stages are particularly important in establishing a community-wide culture and infrastructure for sustained involvement of community action members. These initial stages are essential within the developmental and stage paradigms of organizational advancement. The developmental model of organizations is similar to that of the PYD paradigm: it assumes that organizations mature when they realize the potential inherent to their foundations (Van De Ven \& Poole, 1995). The idea of stages adds to this pattern, in that it assumes natural breaks in this developmental pattern where stakeholders may engage in adaptive activities (Kamm \& Nurick, 1993). Based on these paradigms, the initial planning stage is extremely important to coalitions' success. Yet, the primary focus of extant studies has been the evaluation stage. This has enabled scholars and practitioners to identify successful programs, but the foundations of these successes often remain unknown or obscure. There 
remains a paucity of literature addressing the ideological and structural elements of the planning and implementation stages that are necessary for broader community success. Here, we focus on those specific stages as we investigate the RB21 Coalition.

\section{THE CAF IN PRACTICE: RB21'S APPLICATION OF A THEORY-BASED MODEL}

RB21 Austin/Travis County is based in Travis County, TX, but welcomes participation of organizations in adjacent counties, as well. Travis County, with a county seat of Austin, is located in central Texas and contained just over one million residents in 2009 (U.S. Census Bureau, 2010). The area has a large Hispanic population (33\% Hispanic) and a median household income just above $\$ 55,000$ (U.S. Census Bureau, 2010). The $14.4 \%$ of individuals in Travis County living below the national poverty rate represents a population slightly above the 2008 national percentage of 13.2 (U.S. Census Bureau, 2010). RB21 Austin/Travis County has grown from a small network of cooperatively functioning individuals representing community-based organizations into a comprehensive coalition of organizations. RB21 Austin/Travis County had eight distinct project teams during this period of research that were active or concluding operations. Teams worked independently toward specific goals, but simultaneously worked collaboratively within the RB21 framework. The work teams are:

1. Youth Services Mapping Team,

2. Youth Program Quality Team,

3. Youth Engagement Team,

4. Youth Aging Out of Foster-Care Team,

5. Go to College Team,

6. Millennium (Youth Complex) Team,

7. Juvenile Support/Youth Justice Team, and

8. Adolescent Health Team.

The full coalition meets once per month. Work teams establish their own additional meeting schedule according to work demands. Membership in RB21 has no cost and carries no formal responsibilities except to abide by the ground rules, which are: (a) honor the work that has come before-welcome new people and ideas, (b) openness — share your ideas, listen to others with respect, (c) systems thinking — not limited by special interests, (d) creativity, (e) take responsibility for collective success, and (f) the facilitator has the team's permission to keep the group on task and on time.

\section{METHODS}

We present a case study to report on a cluster of strategies used to answer the core research question of: How well does the RB21 Austin/Travis County corresponds to the CAF? Participant observation, interviews, and archival strategies were integrated to capture the wealth of information related to this complex and dynamic coalition. Employing these strategies collectively allowed us to better document the evolution of the initiative and to better utilize various sources of information on the coalition's multiple components.

\section{Participant Observation}

Participant observation was employed between January 2007 and April 2010. Field notes were kept for each meeting and written mostly during the core meeting times. One investigator has been a coalition member since January 2007, serving as the representative of an affiliated University. This investigator 
was also active in the Youth Program Quality Team, with planning and operational responsibilities similar to other team members. An emphasis was to observe the connections between this work team and the larger coalition. In-kind support for database construction and management helped for tracking program assessments. Community-based activities and events directly and peripherally linked to RB21 Austin/Travis County were attended, and both investigators participated in one steering committee meeting.

\section{Interviews}

Four semistructured interviews were conducted with key stakeholders, including the lead organizer and several coalition members. These individuals were selected because they were active, visible, and important contributors within RB21, but also represented sufficiently divergent home community-based organizations. These coalition members were also requested for interviews because of their longstanding leadership roles and understanding of coalition history. We conducted a limited number of interviews because we were neither using them for representativeness nor for generalizability. Interviews helped fill information gaps in our efforts to better understand historical and current RB21 dynamics. We utilized a semistructured interview guide to help structure but not limit respondent information. Questions included: What brought you to Ready by 21? What things keep you active as a member? What do you see as the biggest challenges to sustaining the vision of RB21? In what ways can RB21 improve to better meet the needs of both coalition members and the broader community?

\section{Archival Strategies}

An extensive review of available historical records was conducted. Meeting agendas and minutes, facilitator notes, progress reports and World Wide Web website information (Ready by 21 Austin, 2011a) were examined to provide contextual data about RB21 Austin/Travis County. Records dated back to 2003 and the coalition's first interest group meeting. Permission to access these data was granted by the Coalition Facilitator and steering committee.

\section{Analytic Plan}

Our analytic strategy sought to determine how the RB21 initiative serves as a model of the CAF in practice, and how it does not. We identified aspects of the organizational structure and activities during the planning and implementation stages that conformed to CAF dimensions. Although the evaluation stage was beyond the scope of this article (i.e., boxes B and A), we separated out RB21 planning and implementation strategies directed toward the eventual measurement and evaluation of long-term and short-term youth outcomes. Each model dimension is examined in relation to coalition activities.

\section{RESULTS}

By the end of our analysis, we were able to map RB21 activities directly onto the stages modeled by CAF. We attempted to identify concrete examples of the theoretical concepts modeled in each of these stages-planning, implementation, and evaluation. Overall, RB21 successfully reproduced all but two of the CAF's many core concepts.

\section{The Planning Stage}

When Boxes E and D in the CAF's model are combined, they indicate that five core tasks should be completed during the planning stage. In the following, we investigate these core tasks and find that 
RB21's organizational structure and concerted activities provide at least one illustration of a way to complete all but one of the tasks.

\section{Establish collective acceptance of a CAF that is understood and valued by all stakeholders}

In 2003, an ad hoc youth advisory group met to begin planning a partnership-based system of youth services. The group organized a Youth Issues Forum that sought to inspire action to better meet the needs of young people in the region. The ad hoc group identified two priority areas on which to focus: (a) communication with and engagement of stakeholders and (b) development of a continuum of services for youth. The original ad hoc group adopted the PYD framework put forward by the Forum for Youth Investment (2010) because it aligns with these primary areas and their aspirations for a working model for change. According to interviews with original participants, the group was also drawn to FYI because it was easy to comprehend, based on strong evidence, and covered important developmental dimensions.

The PYD perspective and dashboard framework provided by the Forum for Youth Investment resources allowed RB21 to quickly establish a shared language and common culture among the original ad hoc members. The widely available literature, manuals, and training documents provided by the Forum for Youth Investment facilitated subsequent efforts to integrate other stakeholders into this collective consciousness. RB21's success in this regard is documented by agreed-upon outcomes and indicators (see the RB21 Priority Outcomes) and, more important, the willingness of other community coalitions and stakeholders to incorporate these outcomes into their own planning efforts (i.e., mobilization for change and action).

\section{Institute a vehicle for sustaining conversations about resource allocations and policies, disseminating and communicating products, and monitoring and readjusting “investments"}

The steering committee serves as a vehicle for ensuring that RB21 continues to have conversations about coalition resources, products, and investments. Its primary responsibility is to ensure that the coalition initiates actions in line with its original or modified goals. Once outcomes and indicators were established by the core Coalition membership, the RB21 steering committee delivered an initial presentation of them to broader stakeholders, including representatives from several important local coalitions and collaborations. For example, the steering committee engaged leaders and high-level staff members from the Community Action Network's partner agencies. The next stage included a series of work groups among regional service providers including school districts and public and private youth serving organizations to adjust the desired outcomes to represent realistic, measurable items.

During this study, representatives from the County's Health and Human Services Department, the nonprofit Community Action Network, Austin Independent School District (AISD), United Way Capital Area, Workforce Solutions, along with a youth representative and other key stakeholders comprised the steering committee. The diversity of membership and lack of hierarchical positions — both of which might impede an organization led by a board of directors or president—help the steering committee to serve as a vehicle for continued discussion of policies, products, and resources investments. Furthermore, the widely varying expertise and professional associations of the committee members facilitates conversations that span the local, regional, and even national level (the latter is due primarily to the assistance of Forum for Youth Investment liaisons). For example, at the national level, RB21 Austin/Travis County credits Bartholomew County, IN, and the Forum for Youth Investment for sharing samples of RB21 Dashboards (Ready by 21 Austin, 2011a). Yet regionally, the United Way Capital Area and Workforce Solutions Capital Area helped convene and facilitate the meetings to implement the dashboards by providing meeting space, financial support, and leadership for coalition activities. 
Strengthen the capacities of community adults (parents, families and primary caregivers, neighbors and employers) to provide support and identify opportunities for youth

The Youth Service Mapping system was developed to serve Austin/Travis County "as a planning resource for aligning and improving services for children and youth” (Ready by 21 Austin, 2011b). It is a Webbased information database organized around the RB21 Dashboard; created to help map the landscape of youth services. Service providers and organizations can enter a program profile of information about their offerings within the RB21 developmental categories of: learning, working, thriving, connecting, and leading/contributing. The Youth Service Mapping system was created to help youth service professionals, educators, policy-makers, and funders identify available services for children and youth, and discover where they are offered. However, the system is a resource for parents, caregivers and others as well. It is geared toward programs offered by both nonprofits and public providers. The coalition also uses the Youth Service Mapping system as a vehicle for improvement, as it can help to identify gaps in services.

\section{Reform and integrate schools and other public institutions and services affecting youth}

The Youth Service Mapping system's functionality considerably benefited public agencies such as the AISD. The AISD is now able to: generate a report of the services offered by different programs and organizations in their schools, view a report of services offered in nearby community settings, and review school needs against existing services so that they can propose any necessary additional partnerships with organizations to best meet needs. A city planner could also use the Youth Services Mapping System to review data trends on youth issues across the entire community and assess the availability of appropriate services in specific areas. Additionally, service providers can use this information to match their grant strategies to gaps in services and, thus, reduce duplication (Youth Services Mapping System, 2009).

\section{Realign public policy and resources to support these community strategies}

RB21 has been less successful in affecting public policy priorities and funding initiatives, when compared to other dimensions of the CAF model. The city of Austin and Travis County agency administration have been increasingly involved in RB21 activities, suggesting a dialogue around potential policy changes regarding service delivery strategies. However, nothing formal has been declared.

\section{The Implementation Stage}

Box $\mathrm{C}$ of the CAF focuses on efforts to actively implement programming. Critical elements of successful programming included the following supports and opportunities for youth: adequate nutrition, health and shelter; multiple supportive relationships with adults and peers; meaningful opportunities for involvement and membership; challenging and engaging/interesting activities and learning experiences; and physical and psychological safety. We found that RB21 integrates all of these supports in two main groupings, recruitment and improvement.

\section{Recruitment and involvement of organizations/agencies that ensure adequate nutrition/health and foster intergenerational, supportive relationships}

RB21's initial efforts at programming were efficient: they involved recruiting agencies already addressing elements critical to setting the stage for PYD. For example, due to the essential nature of nutrition, health, and safety, local and state government agencies have mandates to ensure that these services are offered to youth. Hence, RB21 turned to state agencies with these mandates-City of Austin Health \& Human Services, Travis County Health \& Human Services, Housing Authority of the City of Austin, Austin Police Department — and integrated them as member organizations of the coalition. 
RB21 also initiated ties with groups more typically or traditionally identified as youth-serving organizations. A core group of these member organizations provide youth with the opportunity to develop supportive relations with local adults. For example, one of the project teams was the Youth Engagement Project Team, working to solidify youth engagement with key stakeholders and decision-makers. Fostering relationships with caring adults is very common in youth intervention efforts through services such as tutoring, mentoring, parental training, and artistic performances. However, less common in youthserving efforts is the opportunity for youth to serve others through civic engagement.

The coalition aspect of RB21 has introduced the opportunity for youth to build supportive relations with peers through the recruitment/involvement of organizations such as Youth Launch and Youth Mobilizers (of the Austin Voices for Education and Youth). The coalition also had an active youth member on the steering committee. These efforts ensure that RB21 fosters supportive, reciprocal relations that span the life-course and empower youth, rather than cultivate a culture where adults provide charity to youth.

\section{Improving the ability of existing programs to offer meaningful opportunities, challenging activities, and safe environments to participating youth}

Critical among RB21's strategies to support coalition members was the adoption of the Youth Program Quality Improvement (YPQI) system from the Weikart Center for Youth Program Quality. The Forum for Youth Investment awarded RB21 a 2-year Quality Counts grant to: (a) align youth policy, leadership, and resources; (b) develop a strong program base and data map of youth programs and services; (c) develop the competence to assess and improve programs; and (d) build the capacity to recruit, train, and retain the right staff to provide high quality services to youth. Adopting the YPQI established a structure to help organizations and other stakeholders develop, assess and - if need be-enhance their efforts to support youth.

The YPQI process is a program- and staff-level professional development initiative that seeks not only to increase the number and quality of developmental activities for Austin area youth, but also to align already existing community-based quality improvement/professional development efforts. The YPQI uses measurement tools such as the Youth Program Quality Assessment (Smith, Akiva, \& Henry, 2006) to help youth serving programs determine whether they provide: (a) a safe environment, (b) a supportive environment, (c) interaction, and (d) engagement.

Initial findings suggest that participating organizations benefit the most from longer-term YPQI involvement, which allows them to adopt a common language and attain greater familiarity with the assessment tools. One such organization is, again, the AISD. An interview with a representative of one of the school district's core out-of-school time (OST) programming initiatives shed light on both the value of RB21 and the quality improvement process. The representative discussed her initial involvement in the coalition, followed by a lull in engagement. She mentioned that the YPQI professional development initiative helped revive her interest in RB21 because of its direct applicability to everyday activities in afterschool programming. She explained that, although half of workers have a "passion" for their work, there was the potential for the YPQI to help better engage those that were present because it is "a job." This is one example of the primary benefits of member/organizational involvement with the YPQI: in this case, it seems to have improved the programs, as well as the capacity of staff to continue improving quality and policy among afterschool programming.

\section{Evaluation Stage}

In this study, we are primarily concerned with illustrating RB21's specific strategies that converge with the CAF. Although we are now addressing the evaluation stages, we are not concerned with evaluating RB21's successes or failures in affecting developmental or adult outcomes. In line with our illustrative 
goals, this section details the organization's concrete plans and actions-i.e., their established infrastructure-deemed by the CAF to be essential to the eventual evaluation of the program's effectiveness.

Through an iterative process, RB21 stakeholders came to consensus on 17 outcomes that will be used to gauge progress toward the coalition's goals. The majority of these outcomes span the youth's potential involvement with the program: from birth through age 24 (Table 1). However, some of these outcomes are specific to what the CAF terms developmental ages although other, long-term outcomes are specific to adult ages. The outcomes, themselves, indicated that RB21 has come to consensus on a set of measurable outcomes that conform to the program's goals and address all aspects of Boxes A and B in the CAF: CAF's delineated developmental and long-term outcomes.

The CAF proposes that programs should aim to improve youth developmental outcomes in three specific ways. According to the model, programs should simultaneously help youth (a) learn to be socially and economically productive, (b) develop emotional connections with caring and supportive individuals, and (c) gain skills to successfully navigate potentially positive as well as potentially negative social situations. The program goals listed in Table 1 utilize RB21's original labels. Thus, the information in the table shows that the program addresses each of these three categories of developmental outcomes in the following ways:

1. Learn to be socially and economically productive: In their own words, outcomes in RB21's Learning and Working categories are designed to measure basic academic ability, college readiness, and work/career awareness and readiness.

2. Learn to emotionally connect with caring and supportive individuals: Outcomes listed under Connecting specifically conform to these criteria as they aim to measure youths' "interpersonal/social connections and well being” (Ready by 21 Austin, 2011c).

3. Learn to successfully navigate social situations: RB21 identified outcomes listed under Leading/Contributing as indicative of “civic engagement” (Ready by 21 Austin, 2011c). Although the members, themselves, have included the desire for youth to "engage in community, school and/or extracurricular activities” (Ready by 21 Austin, 2011c) as a measure of Connecting, we have reclassified it as a measure of leading/contributing because it is more inline with the CAF stipulation to learn to navigate social situations.

The CAF indicates that services for youth should plan to have a long-term effect; and all of the aforementioned outcomes are important because they have long-term effects on youths' life chances. In this way, CAF calls for action and planning to directly or indirectly improve adult outcomes. According to the framework, services might continue into adulthood, but even if they do not, the developmental, physical, and emotional effects of programs during childhood and adolescence are only truly successful if they continue to affect pertinent outcomes in young adulthood and beyond.

RB21's planning and implemented efforts seemed to take this message to heart. As indicated in Table 1, 10 of the 17 established outcomes will be measured between ages 20 and 24; that is, in young adulthood. Furthermore, RB21's identified measures address two of the three most important adult outcomes identified in the CAF:

1. Economic self-sufficiency: RB21 plans to measure homelessness, percent idle, and financial literacy as indications of economic self-sufficiency in young adulthood. 
2. Community involvement: RB21 will assess volunteer rates, participation in leadership or advisory groups, and awareness/concern about social issues to determine community involvement in young adulthood.

These represent sound and comprehensive measures of the intended concepts. However, a gap exists in measures of healthy family and social relationships in young adulthood, as measures of these concepts have been confined to the youth context.

Although RB21 has not yet reached the evaluation stage, the coalition has discussed intended outcomes throughout the developmental ages and into adulthood. Furthermore, consensus has been reached on a set of concrete, measurable outcomes to correspond to each of the life-stage specific goals. RB21 has also completed baseline data collection on each of these outcomes and the associated indicators. Historical data has been collected for all 17 outcomes, and data have been benchmarked with four comparison groups: (a) the previous year, (b) 3 years prior, (c) data on the state of Texas, and (d) data on the US population. A subcommittee on outcomes and indicators has been established to help develop and track a scorecard that will also allow further comparisons to state and national indicators.

\section{Summary of Findings}

The RB21 steering committee, active community engagement, and a youth service mapping system anchored the planning dimensions of the CAF (Boxes E and D). Strategic recruitment and involvement of organizations, active youth engagement and a strong structure for quality improvement were the foundation of a robust implementation dimension of the CAF (Box C). Finally, although we did not evaluate the program itself, well-defined, consensus-driven, and measurable outcomes have been established, allowing internal or external evaluation in the future (Boxes B and A).

Thus, our findings indicate that RB21's experience can be used to illustrate the applied utility of the CAF model. Each of RB21's strategies that fulfill CAF requirements is listed in the following figure (Figure 2); as other youth-based coalitions may want to refer to these efforts as a realistic model. Also listed within the Figure 2 in bold are the two requirements that RB21 has struggled to fulfill (i.e., official policy and procedural buy-in from the city/county administration and measurement of adult relationships).

The example of RB21 indicates that —at least on the ground — it may be more appropriate for the CAF to model three stages related to the planning, implementation, and evaluation of coalition efforts, instead of five independent stages. Within each of these stages, there is substantial interreliance between the original/separate boxes. Further, we have added feedback arrows between assessment of outcomes and planning community strategies. These arrows more appropriately reflect the iterative process in which RB21 engaged.

\section{DISCUSSION}

The underlying question in this study asked whether RB21 Austin/Travis County could be used to provide applied examples of theoretical dimensions in the CAF proposed by Gambone and colleagues. Results were favorable and offered clear examples of the CAF's applicability to coalition-based community work, while acknowledging opportunities for refinement. Issues were revealed that should be considered by anyone (or any group) interested in the CAF or other community youth development strategies. We proposed a revised model to account for information feedback loops, simultaneous work pathways within RB21, and overlapping framework dimensions. 
We also sought to investigate concerns that the theoretical framework proposed in the CAF is too complex and multidimensional to be of practical use to grassroots organizations. Our analysis indicates that the model is not too complex for community adoption. On the contrary, RB21's experiences help us to understand the context of theoretical complexities. Specifically, the observed on-the-ground reality suggests that complexities may occur with the adoption of the CAF model, but facilitative conditions include: a broad service theme, a significant amount of time for planning prior to implementation, heterogeneous social networks, and symbiotic stages in the organization's development. Youth development coalitions may benefit from consideration of these strategies.

\section{Broad Service Theme}

Adopting a broad service theme allows coalition members to be connected, yet unique. Our data indicated that the organizing issue has to be broad enough for different people and organizations to feel ownership/expertise in a specific area. This finding mirrors the results of research by Imm et al. (2006) that showed specialization but not isolation among discreet intracoalition groups. The youth development frame of RB21 is broad enough for many stakeholders to find a home, yet specific enough for them to feel connected. This principle of inclusivity and respect for specialties can be seen throughout the organization. For example, within the Coalition, the Youth Aging Out of Foster Care project team further diversified with (a) housing, (b) education and workforce development, and (c) advocacy subcommittees. Thus, evidence suggested coalitions should develop broad themes that allow for cohesion.

\section{Planning Time}

Developing consensus requires a substantial amount of time up front. Data suggested that creating an organic and universally acceptable vision, and then developing a structure within which change can occur takes significant time and resources. For this coalition and its resident communities, the start up process took several years. For example, only during the last year has an accepted compendium of youth outcomes and indicators emerged. This is a normal and acceptable period of time, but it helps illustrate the importance of patience and realistic expectations for developing a complex, multifaceted communitybased initiative. It remains to be seen how the intersection of time and resources unfolds, as current funding is inconsistent. Nonetheless, time and energy for large-scale change must be consistent.

\section{Heterogeneous Network}

The membership should consist of individuals/organizations that allow access to heterogeneous resource pools. Data indicated that RB21 Austin/Travis County has multiple, overlapping intra-coalition systems and dense inter-coalition networks operating in each box of the CAF model. For RB21 Austin/Travis County, (a) the steering committee, (b) the large group coalition, and (c) project teams operated as semi autonomous task groups, but worked toward similar broad RB21 objectives. From a social network perspective, external coalitions and organizations were involved with each intracoalition system. These ongoing and dynamic relationships added a substantial level of complexity when applied to the CAF. Yet, they protected against the coalition continuing to draw upon (and eventually exhausting) homogenous "resource pools" (Jarrett \& Burton, 1999, p. 181), including volunteers, funding sources and knowledge bases.

\section{Symbiotic Stages}

Stages within the framework should be seen as symbiotic, instead of linear. When examining the accomplishments of the coalition and how new objectives emerged within the context of the CAF, data indicated that substantial feedback loops existed in the framework. Exact feedback pathways must be 
specified and tested in the future. Nevertheless, when taking a snapshot of the relationship between the CAF and RB21, it appeared that communication occurred at a high level across boxes/framework dimensions, and not just via the unidirectional arrows presented in the original Gambone et al. (2002) framework. Thus, concerns about the potential complexity of the model appear even less warranted because the applied reality seems to be more complex than the original framework.

For example, when revisiting Box E-or the planning stage-it seems that if the core philosophy is strong, then a coalition can be flexible in its processes. At the very least, when using the CAF, programs should consider moving from evaluation of short- and long-term youth outcomes back to planning efforts and the theoretical orientation. If this feedback loop does not exist, the evaluation stage is purely a terminal stage, rather than an opportunity for reflection and improvement. Instead, the evaluation stage should be thought of within the framework of stages in organizational development: an opportunity to pause and develop a more refined approach to building awareness, demonstrating urgency, capacitybuilding and implementing procedures.

In this way, the functions of the program quality team and the subsequent impacts on the theoretical development of the coalition serve as an example of feedback loops in action. The quality improvement process involves assessment, dissemination of the assessment results, professional youth development training, reinforcement/support of the core ideology, further assessment, and further reinforcement/support. These processes continuously operate in a circular pattern within the CAF as boxes $\mathrm{D}$ (planning stage) and $\mathrm{C}$ (implementation stage). Due to this type of symbiotic relationship, RB21 Austin/Travis County seems to be evolving into an improved organization instead of approaching the end of its development. An expansion of the steering committee that seeks to strengthen its social network ties has accompanied the completion of several major projects. This improved organization-perhaps best described as RB21 2.0 — seems to be reintroducing a new round of capacity building and community strategies to enhance supports and opportunities.

\section{RB21 Challenges}

Unknowingly implementing key tenets of the CAF seems to have enhanced RB21's development. At the same time, RB21 has provided valuable examples of the individual elements of the CAF and offered guidance to community youth development coalitions. Yet, RB21's experience is not completely and seamlessly represented in the CAF. The coalition continued to face challenges that are not addressed by the framework. Many of these challenges fall into one of two categories: reflexive learning and sustainability.

First, the CAF does not provide a systematic opportunity for the coalition as a cohesive organization to integrate information from lessons learned about its own effectiveness or resource development opportunities. The model assumes that knowledge is a top-down process, flowing from academics and government agencies to the membership. However, can the coalition generate knowledge itself? In the case of RB21, participants in the quality improvement process have the opportunity to note their improvement and document shortcomings. Yet, RB21 as a full coalition has had limited opportunity, thus far, to learn about what is important for PYD based on its own successes and failures. Similarly, the coalition has little access to knowledge about the magnitude or quantity of (a) available resources to or (b) increased resources/capacity from coalition activities for the coalition as a whole or its members. They have few structured opportunities to assess, for example, the relevant funding available from government agencies or foundations. Instead, the sharing of information concentrates almost exclusively on official information and informal resource and knowledge sharing.

Second, issues of sustainability remain unclear in both RB21's experience and the CAF's model. The model provides little guidance regarding individual or group accountability for change within the 
coalition format, and RB21 has yet to answer this question. Even responsibility for the proximate elements of change (for example, disseminating information) is ambiguous. Beyond these general questions, the model also fails to provide guidance on the more logistic, but common obstacles facing coalitions. For example, RB21 continues to need guidance on how to appropriately budget (specifically within the planning stage) for a long-term coalition-led initiative and how to approximate/predict changes in available resources that will impact the coalition. This study begins to fill a gap in the applied knowledge about implementing CAFs, but more applied research is needed to present examples and guidance on these remaining inconsistencies.

\section{Conclusions}

The implications of this study should be interpreted with consideration of several limitations. The analyses conducted were not of a random sample of participating organizations or coalition members. Thus, interview data were a result of convenience sampling and should not necessarily be viewed as generalizable to all individual participants or all coalition organizations. Further, findings related to the RB21 Austin/Travis County coalition should not be considered indicative of other national RB21 initiatives or other community-based youth development efforts.

Nonetheless, our results support prior research suggesting that a guiding framework for community-based youth development and coalition efforts can be of great value. Further, results highlighted how improvements in youth health and well-being are a result of a host of reciprocal relationships existing across that youth's ecology. They provide guidance to practitioners, indicating that efforts must be sustained at the direct service provider level, but a collection of equally important macro-level energies must accompany direct service.

The results also provide guidance to scholars. All of our findings can be translated back into the language of PYD. During the planning stage, full consideration of preconditions for proper development served as evidence of a distinct, applied focus on helping youth to develop internal assets. Consistent with PYD literature, stakeholders were invested in the strengths and possibilities of youth, and sought strategies for investing in the ecology of youth to maximize their positive health and development (Damon, 2004; Lerner et al., 2005). Results also showed that the coalition format, with strong network ties among members and with other coalitions, can be an effective vehicle for strengthening positive developmental settings. Coalitions can be a conduit for external assets at multiple ecological levels to build upon each other (Lerner \& Castellino, 2002).

Community-based strategies to promote PYD and program quality are well-documented (Bodilly et al., 2010; Durlak \& Weissberg, 2007; Eccles \& Gootman, 2002; Lerner et al., 2005; Yohalem, Granger, \& Pittman, 2009), but our study suggests that coalitions may uniquely assist in the full implementation of PYD concepts. To further advance the rich body of literature employing a PYD framework, more systematic exploration of coalitions is warranted. Further, the efficacy of the CAF, or the ability of the framework to contribute to health and well-being should continue to be monitored. The CAF appears to offer a clear and meaningful template for planning, practice, and evaluation. The discussed research was presented in a case study format for illustrative purposes, but a more comprehensive research design should test our conclusions. More specifically, additional research can determine the magnitude by which capacity-building manifests in coalition-based efforts in comparison to noncoalition efforts. Further, scholars should specifically focus on how well coalitions establish an integrated knowledge generating process linked to coalition activities, such as feedback mechanisms for quality improvement efforts. In this way coalition members can learn from coalition activities just as much as they do from national expertise. Further, more research is needed on effective strategies for promoting sustainability among coalitions where there is not necessarily a centralized entity that assumes financial accountability. Organizations and coalitions could benefit from scholarship that outlines best practices for financial 
planning, budgeting, resource development, and contingency planning for resource instability within youth-focused coalitions.

This study offers substantive examples of the potential value of implementing the CAF for communitybased youth initiatives. Similarly, it highlights the fact that coalition-led efforts can be valuable to communities in the same capacity as organization-led efforts. The challenges RB21 Austin/Travis County has faced are minor when compared to the dynamic, engaged, and socially meaningful role that they play within this region. RB21 provides several concrete examples of how to operationalize the CAF. Both traditional organization-led efforts and coalition efforts can implement the CAF, or other theory-based, community-level youth development strategies, at the full level of model complexity.

\section{Acknowledgments}

We acknowledge Ready by 21 Austin/Travis County, United Way Capital Area, $21^{\text {st }}$ Century Community Learning Centers of Austin Independent School District and other coalition members for their support of the development of this article. 


\section{REFERENCES}

1. Arthur, M. W., Hawkins, D., Brown, E. C., Briney, J. S., Oesterle, S. and Abbott, R. D. 2010. Implementation of the communities that care prevention system by coalitions in the community youth study. Journal of Community Psychology, 38(2): 245-258.

2. Benard, B. 1997. Turning it around for all youth: From risk to resilience. Eric/Cue Digest, 126: 17.

3. Benson, P. L. 2002. Adolescent development in social and community context: A program of research. New Directions in Youth Development, 95: 123-147.

4. Blinn-Pike, L. 1999. Why abstinent adolescents report they have not had sex: Understanding sexually resilient youth. Family Relations, 48(3): 295-301.

5. Bodilly, S. J., McCombs, J. S., Orr, N., Scherer, E., Constant, L. and Gershwin, D. 2010. Hours of opportunity: Lessons from five cities on building systems to improve after-school, summer school, and other out-of-school-time programs, Santa Monica, CA: RAND.

6. Brackenreed, D. 2010. Resilience and risk. International Education Studies, 3(3): 111-121.

7. Brennan, M. 2008. Conceptualizing resiliency: An interactional perspective for community and youth development. Child Care in Practice, 14(1): 55-64.

8. Brooks-Gunn, J., Duncan, G., J., Klebanov, P. K. and Sealand, N. 1993. Do neighborhoods influence child and adolescent development?. American Journal of Sociology, 99(2): 353-395.

9. Damon, W. 2004. What is positive youth development?. Annals of the American Academy of Political Social Science, 591: 13-24.

10. Durlak, J. and Weissberg, R. 2007. The impact of after-school programs that promote personal and social skills, Chicago, IL: Collaboration for Academic, Social and Emotional Learning.

11. Eccles, J. S. and Gootman, J. A. 2002. Community programs to promote youth development, Washington, D.C: National Academy of Science.

12. Forum for Youth Investment. (2010). The forum for youth investment. http://forumfyi.org/ (http://forumfyi.org/)

13. Gambone, M. A. and Connell, J. P. 2004. The community action framework for youth development. The Prevention Researcher, 11(2): 16-20.

14. Gambone, M. A., Klem, A. M. and Connell, J. P. 2002. "Finding out what matters for youth: Testing key links in a community action framework for youth development". In Youth Development Strategies, Philadelphia, PA: Institute for Research and Reform in Education.

15. Imm, P. S., Kehres, R., Wandersman, A. and Chinman, M. 2006. Mobilizing communities for positive youth development: Lessons learned from neighborhood groups and community coalitions, New York, NY: Springer. 
16. Jarrett, R. L. and Burton, L. M. 1999. Dynamic dimensions of family structure in low-income African American families: Emergent themes in qualitative research. Journal of Comparative Family Studies, 30: 177-188.

17. Jelicic, H., Bobek, D., Phelps, E., D., Lerner, J. V. and Lerner, R. M. 2007. Using positive youth development to predict contribution and risk behaviors in early adolescence: Findings from the first two waves of the 4-H study of positive youth development. International Journal of Behavioral Development, 31(3): 263-273.

18. Kamm, J. and Nurick, A. 1993. The stages of team venture formation: A decision making model. Entrepreneurship Theory and Practice, 17(2): 17-27.

19. Kotloff, L. J. and Korom-Djakovic, D. 2010. AfterZones: Creating a citywide system to support and sustain high-quality after-school programs, Philadelphia, PA: Public/Private Ventures.

20. Lerner, R. M. and Castellino, D. 2002. Contemporary developmental theory and adolescence: Developmental systems and applied developmental science. Journal of Adolescent Health, 31(6): 122-135.

21. Lerner, R. M., Lerner, J. V., Almerigi, J. B., Theokas, C., Phelps, E.Gestsdottir, S. 2005. Positive youth development, participation in community youth development programs, and community contributions of fifth-grade adolescents: Findings from the first wave of the 4-H study of positive youth development. Journal of Early Adolescence, 25(1): 17-71.

22. Oman, R. F., Vesely, S., Aspy, C. B., McLeroy, K., Rodine, S. and Marshall, L. 2004. The potential protective effect of youth assets on adolescent drug use. American Journal of Public Health, 94(8): 1425-1430.

23. Pittman, K. 2009. Thinking outside the box: Creating catalytic partnerships to change the odds for children and youth, Washington, D.C: Forum for Youth Investment.

24. Ready by 21 Austin/Travis County. (2011a). http://www.readyby21.org

(http://www.readyby21.org)

25. Ready by 21 Austin/Travis County. (2011b). Youth Services Mapping (YSM) Team. http://www.readyby21austin.org/component/article/77.html (http://www.readyby21austin.org/component/article/77.html)

26. Ready by 21 Austin/Travis County. 2011c. Ready by 21 continuum of youth development: Prioritized child and youth outcomes for crosswalk process.,

27. Resnick, M., Bearman, P., Blum, R., Bauman, K., Harris, K.Jones, J. 1997. Protecting adolescents from harm: Findings from the national longitudinal study on adolescent health. Journal of American Medical Association, 278(10): 823-832.

28. Roth, J. and Brooks-Gunn, J. 1998. Promoting healthy adolescents: Synthesis of youth development program evaluations. Journal of Research on Adolescence, 8(4): 423-459. 
29. Scales, P., Benson, P., Leffert, N. and Blyth, D. 2000. Contribution of developmental assets to the prediction of thriving among adolescents. Applied Developmental Science, 4(1): 27-46.

30. Smith, C., Akiva, T. and Henry, B. 2006. Quality in the out-of-school time sector: Insights from the youth program quality assessment validation study, San Francisco, CA: High/Scope Educational Research Foundation.

31. US Census Bureau, (2010). State \& county quickfacts: Travis county, TX. http://quickfacts.census.gov (http://quickfacts.census.gov)

32. Van De Ven, A. and Poole, M. 1995. Explaining development and change in organizations. Academy of Management Review, 20(3): 510-540.

33. Walker, K. E. and Arbreton, A. J. 2001. Working together to build beacon centers in san francisco: Evaluation findings from 1998-2000, Philadelphia, PA: Public/Private Ventures.

34. Yancey, A., Grant, D., Kurosky, S., Kravitz-Wirtz, N. and Mistry, R. 2011. Role modeling, risk, and resilience in California adolescents. Journal of Adolescent Health, 48: 36-43.

35. Yohalem, N., Granger, R. C. and Pittman, K. J. 2009. The quest for quality: Recent developments and future directions for the out-of-school-time field. New Directions for Youth Development, : 129140.

36. Youth Services Mapping System. (2009). YSM-Youth services mapping system. http://www.ysm-austin.org/ (http://www.ysm-austin.org/)

37. Zief, S., Lauver, S., \& Maynard, R. (2006). Impacts of after-school programs on student outcomes. Campbell Systematic Reviews, 3, 1-52.

http://www.campbellcollaboration.org/lib/download/58/

(http://www.campbellcollaboration.org/lib/download/58/) 
TABLE 1 RB21's Planned, Measurable Indicators

Program goals

Learning

Working

Thriving

Connecting

Leading/Contributing
Developmental outcomes (Age 0Adult outcomes (Age 20 through through age 19)

24)

1. Enter kindergarten prepared 1. Successfully complete to succeed postsecondary education and/or training

2. Are academically successful

3. Graduate from high school college and/or career ready

4. Have awareness and positive 2. Are productive and financially attitudes about adult careers equipped to reach financial self sufficiency

5. Are born healthy

3. Are physically healthy

6. Are physically healthy

4. Are physically safe

7. Are physically safe

5. Have good mental health and are emotionally resilient

8. Have good mental health and 6. Avoid risky behaviors are emotionally resilient

9. Avoid risky behaviors

10. Have significant attachment 7. Demonstrate empathy and to a nurturing adult other pro-social behaviors

11. Have a sense of belonging

8. Respect diversity and engage in a supportive family or with a in diverse relationships caregiver

12. Demonstrate empathy and other pro-social behaviors

13. Respect diversity and engage in divers relationships

14. Engage in community,

9. Engage in community, school school and/or extracurricular activities and/or civic activities

15. Are aware of and 10. Are aware of and demonstrate personal and socialdemonstrate personal and social responsibility responsibility 
FIGURE 1 Community Action Framework adapted from Gambone, Klem, and Connell (2002), describing pathways to improved short and long-term youth development outcomes.

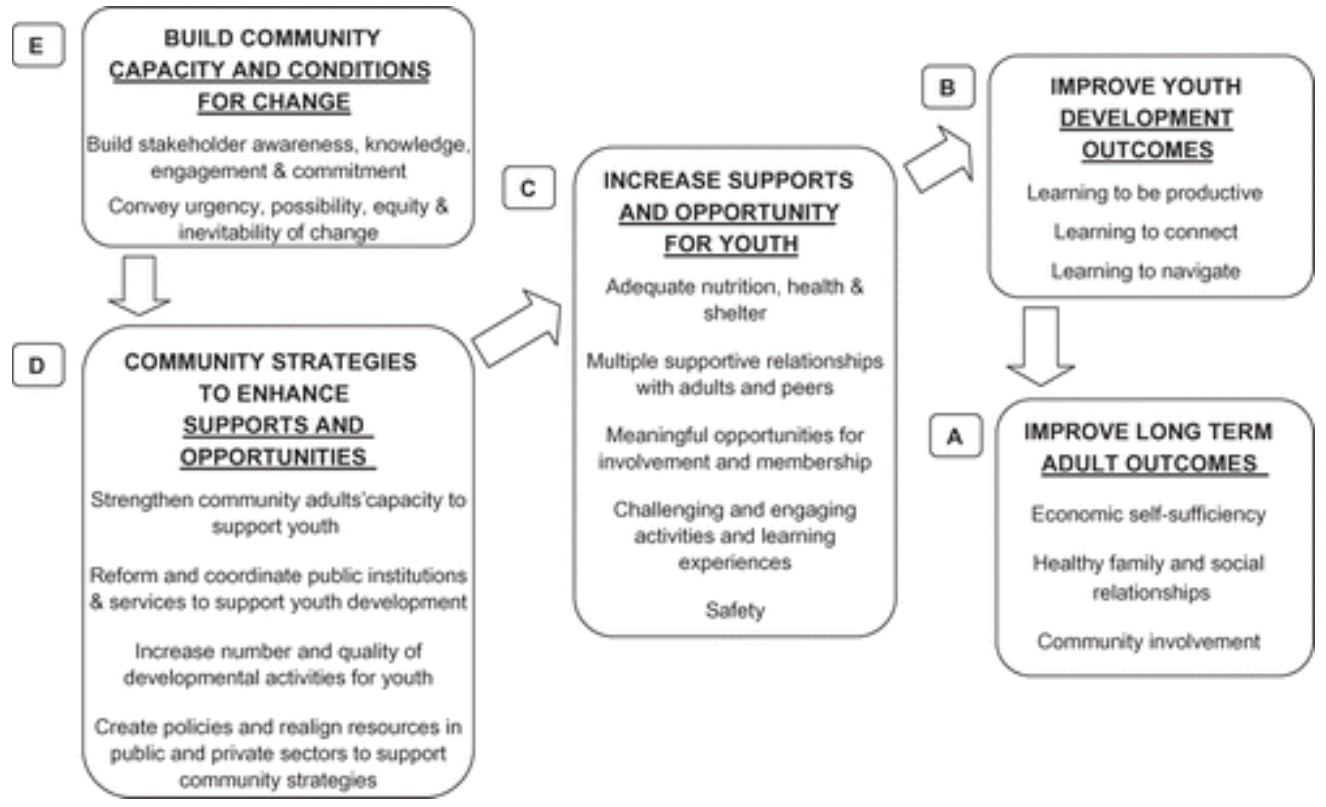


FIGURE 2 Ready by 21 Austin/Travis County Action Framework Model. Adapted from and revised from the Community Action Framework by Gambone, Klem, and Connell (2002).

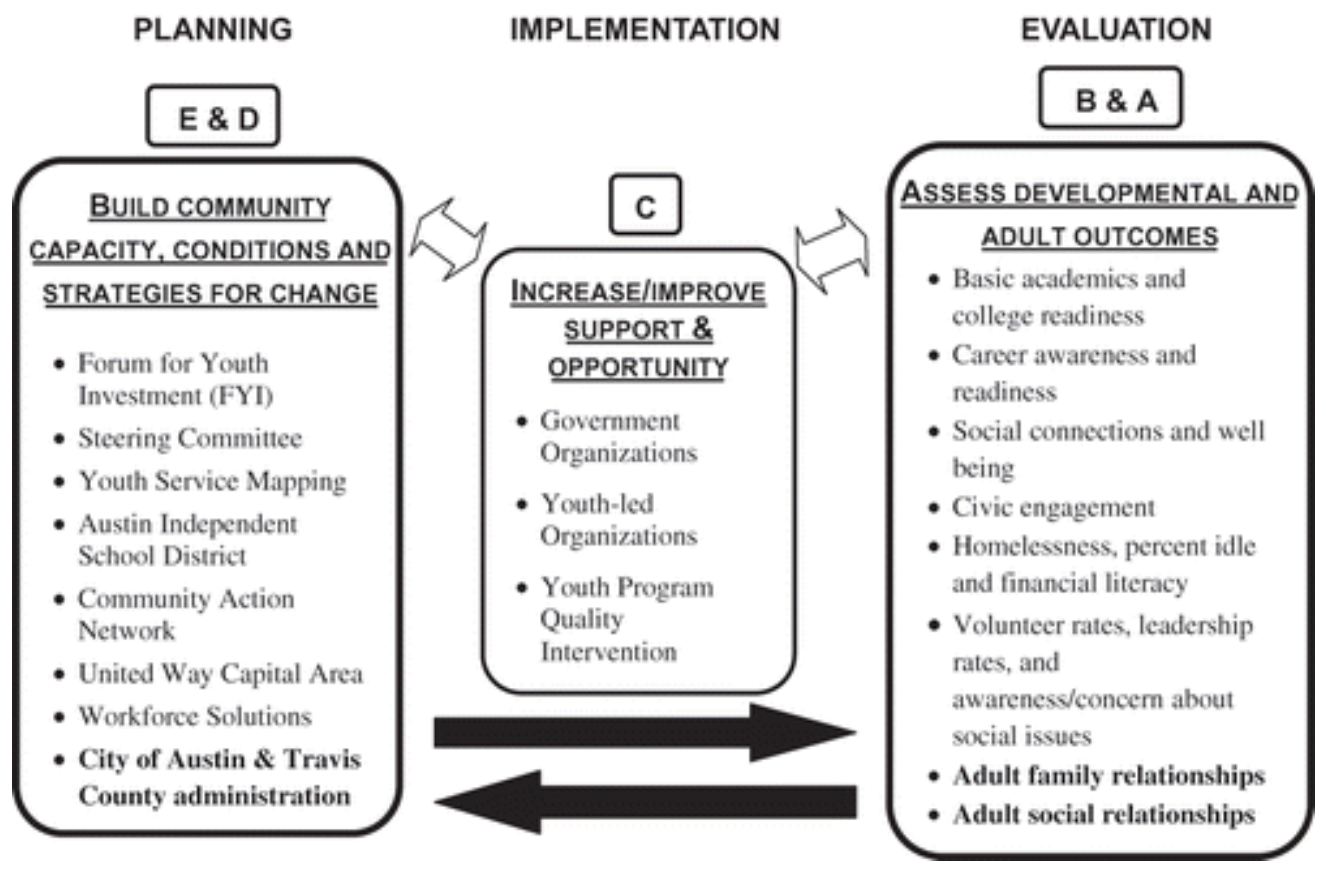

